Kevin Southern ORCID iD: 0000-0001-6516-9083

J.P. Clancy ORCID iD: 0000-0002-9695-097X

\title{
AEROSOLIZED AGENTS FOR AIRWAY CLEARANCE IN CYSTIC FIBROSIS
}

Running title: Airway clearance agents in cystic fibrosis

\author{
Kevin W. Southern MD, $\mathrm{PhD}^{1, *}$, John P. Clancy $\mathrm{MD}^{2}$, Sarath Ranganathan $\mathrm{MD}, \mathrm{PhD}^{3}$ \\ ${ }^{1}$ Department of Women’s and Children’s Health, University of Liverpool, Liverpool, \\ United Kingdom \\ ${ }^{2}$ Division of Pulmonary Medicine, Cincinnati Children’s Hospital Medical Center, \\ Cincinnati Ohio, USA \\ ${ }^{3}$ Respiratory and Sleep Medicine, Royal Children’s Hospital, Melbourne, Victoria, \\ Australia
}

\section{Declaration of interest}

The continuing medical education webinar referred to in the manuscript was funded by an independent medical education grant from F. Hoffman-La Roche Ltd. The authors received an honorarium for the development of the content of and participating in the live webinar. The funding body had no input into the contents of the webinar and the participants had no contact with the funding body.

For the development of this manuscript, support from Roche was limited to editorial services provided by a medical writer (see acknowledgements). The authors controlled the development of this manuscript since its inception including the concept and design, drafting and reviewing/editing and final approval of the manuscript, and take full

This is the author manuscript accepted for publication and undergone full peer review but has not been through the copyediting, typesetting, pagination and proofreading process, which may lead to differences between this version and the Version of Record. Please cite this article as doi: 10.1002/ppul.24306.

This article is protected by copyright. All rights reserved. 
responsibility for it and the views expressed. The authors have received no financial support for this manuscript and have had no contact with any sponsor personnel.

The authors have no other conflicts of interest to declare.

\title{
*Corresponding author:
}

Kevin W. Southern

Department of Women’s and Children's Health, University of Liverpool

Foundation Building, Brownlow Hill

Liverpool, L69 7ZX

Tel: +44 (0) 1512284811 Ext. 3536

Email: kwsouth@liv.ac.uk

\section{Keywords}

Cystic fibrosis, airway clearance, dornase alfa, hypertonic saline, mannitol

\section{Running head}

Aerosolized airway clearing agents in CF

\begin{abstract}
The outlook for people with cystic fibrosis (CF) has improved considerably as a result of conventional therapies including aerosolized agents for airway clearance. These will continue to play a significant role in maintaining well-being and improving survival, even as newer agents emerge that correct the underlying CF defect. In this review, we explore the evidence supporting the use of dornase alfa, hypertonic saline and mannitol in improving mucus clearance in patients with CF from different age groups with differing disease severity. We also discuss the clinical use of these agents in the context of available international guidelines as well as practical considerations in the clinic,
\end{abstract}

This article is protected by copyright. All rights reserved. 
highlighting the importance of a multi-disciplinary approach and shared decision making. Unanswered questions regarding the optimal use of these agents are highlighted.

\section{Acknowledgements}

Medical writing assistance with the preparation of this manuscript was provided by In Vivo Academy Pte Ltd.

\section{Introduction}

The pathophysiology of cystic fibrosis (CF) originates from mutation of the CF transmembrane conductance regulator (CFTR) gene, which leads to an absence or malfunction of CFTR protein. The abnormal CFTR protein disrupts ion transport across cell membranes, resulting in dehydration of the airway surface liquid (ASL) and altered mucus properties and clearance (Figure) ${ }^{1-3}$. The abnormal ASL and mucus impairs mucociliary clearance, allowing mucus accumulation and airway obstruction ${ }^{1}$. This results in an environment for characteristic bacterial infections, inflammation and airways damage. More than 2,000 mutations have been identified of the CFTR gene, categorized into seven classes based on their molecular defect ${ }^{4}$.

Mucus accumulation in the lower airways is an important element of CF lung disease. A major component of this abnormal mucus is polymerized DNA and filamentous actin (Factin) derived from degraded neutrophils (Figure) ${ }^{5}$. The mucus in CF is characterized by increased sputum adhesion and 'stickiness', caused by factors such as reduced $\mathrm{pH}^{3}$ and an abnormal phospholipid balance that alters the surface properties of the secretions ${ }^{5}$.

Conventional management of CF, including excellent nutrition and active treatment of airway infection, has been demonstrated to extend life expectancy of patients with CF beyond 40 years. Symptomatic therapies for CF lung disease include a variety of airway clearance techniques, aerosolized agents for airway clearance (mucolytics and airway hydrators), antibiotics, anti-inflammatory drugs, pancreatic replacement enzymes and vitamin supplementation ${ }^{6}$. A better understanding of the molecular CFTR defect has led to the development of therapies, such as the CFTR modulators ivacaftor, lumacaftor/ivacaftor and tezacaftor/ivacaftor combinations, that correct the defect and

This article is protected by copyright. All rights reserved. 
have proven efficacy in improving respiratory function in adolescent and adult patients with $\mathrm{CF}^{6}$. However, conventional therapies, including aerosolized agents for airway clearance, continue to have a pivotal role in maintaining well-being and improving survival.

This review summarizes the presentations and discussions at an independent continuing medical education (CME) webinar "Aerosolized agents for airway clearance in cystic fibrosis: When, How and Why?”, and provides updated information on the airway clearance agents, reflecting different approaches across the globe. The 1.5-hour CME program included an overview of the role of aerosolized airway clearance agents and adherence issues related to aerosolized CF therapies. Additional PubMed search for randomized clinical trials and systematic reviews (published in English up to the September 2018) was conducted to support the discussion on efficacy and safety of airway clearance agents in this manuscript. Search keywords included cystic fibrosis, recombinant human DNase, dornase alfa/alpha, hypertonic saline, and mannitol; and excluded epidemiology, pre-clinical, cost-effectiveness, non-CF studies, and studies assessing various delivery methods and combination of antibiotics/airway clearance agents.

\section{Aerosolized airway clearance agents}

The aim of airway clearance agents in CF is to prevent the accumulation of mucus and facilitate clearance from the airways; this is believed to reduce the potential for bacterial infection and inflammation.

\section{Dornase alfa (recombinant human DNAse)}

Mucus in CF airways has increased viscoelasticity, due in part to the accumulation of DNA and F-actin ${ }^{5}$. Dornase alfa (recombinant human DNAse) has been shown to degrade DNA and decrease mucus viscosity in vitro and in vivo, confirming a beneficial effect in improving pulmonary function via a reduction in mucus viscoelasticity ${ }^{7-9}$.

Dornase alfa was the first approved DNAse therapy for the treatment of CF lung disease and is available as a $2.5 \mathrm{mg}$ dose for inhalation once daily ${ }^{10}$. The clinical efficacy of

This article is protected by copyright. All rights reserved. 
dornase alfa in patients with CF has been demonstrated in several clinical trials in patients with mild-to-severe lung disease.

In adult patients with mild-to-moderate CF, administration of $2.5 \mathrm{mg}$ aerosolized dornase alfa once or twice daily resulted in an improvement in lung function and a modest reduction in the risk of exacerbations of respiratory symptoms ${ }^{11}$. Continued administration for up to 6 months led to a mean improvement in $\mathrm{FEV}_{1}$ of $5.8 \%$ following once-daily treatment and 5.6\% for twice-daily treatment. Dornase alfa was also associated with a reduced incidence of pulmonary exacerbations, with no difference between once- and twice-daily administration ${ }^{11}$. In patients with severe lung disease, improvement in lung function was only was seen after 3 months of dornase alfa therapy, possibly suggesting a slower response ${ }^{12,13}$.

Longer term studies suggest a continued benefit from dornase alfa on the rate of decline of $\mathrm{FEV}_{1}{ }^{14}$. A Cochrane systematic review of dornase alfa for CF confirmed its role in improving lung function and decreasing exacerbations when compared with placebo improvements in $\mathrm{FEV}_{1}$ were observed within one month of initiating dornase alfa ${ }^{15}$. Postmarketing surveillance in Europe confirmed the findings from clinical trials in routine clinical practice - dornase alfa improves lung function and reduces the incidence of exacerbations ${ }^{16}$.

In addition to reducing pulmonary exacerbations, dornase alfa has been shown to influence the progression of neutrophilic airway inflammation that is seen in untreated patients with CF. The study by Paul et al. found that dornase alfa treatment did not alter the percentage of neutrophils in the bronchoalveolar lavage fluid neutrophils, in contrast to the increase seen in untreated patients ${ }^{17}$. The anti-inflammatory effect of dornase alfa may be an indirect consequence of the lower rate of exacerbations or the improved mucus clearance $^{17,18}$.

In a 2-year study of young patients with CF (6-10 years) and mild lung disease, dornase alfa maintained lung function and reduced the risk of exacerbations ${ }^{19}$. In a short (4 week) cross-over study, a Canadian group demonstrated a small but significant reduction in lung clearance index with dornase alfa compared to placebo in children with CF between 6 to

This article is protected by copyright. All rights reserved. 
18 years of age ${ }^{20}$, further supporting a possible role for dornase alfa in a young population with milder airway disease.

The Cochrane review concluded that there is paucity of data on the efficacy of dornase alfa in improving lung function in children under the age of 6 years ${ }^{15}$. While the data from the Epidemiologic Registry of CF suggests that dornase alfa is well-tolerated in children with CF under 5 years of age ${ }^{21}$, more studies are needed to confirm the benefit of dornase alfa in the pre-school age children.

In clinical trials, dornase alfa was well-tolerated and post-marketing surveillance has been reassuring. Voice alteration and rash were the most commonly reported adverse events $^{15,16}$.

With respect to timing and frequency of dornase alfa administration, current evidence based on a small number of participants suggests no difference when administered before or after airway clearance techniques ${ }^{22}$. Limited evidence also suggests no difference in improvement in lung function or symptoms when dornase alfa was administered in the morning or evening; daily and alternate-day; or once and twice a day ${ }^{11,22,23}$. In the absence of high-quality evidence, the decision on timing and frequency of dornase alfa use may depend on practical reasons or individual preference of the patient. Alternateday use could potentially reduce treatment burden and cost in patients with $\mathrm{CF}^{23}$. While there were no safety concerns over inhalation of dornase alfa prior to bedtime in young patients, this practice in older and more severe patient populations could potentially lead to large amount of mucus being released but not properly cleared during sleep ${ }^{24}$. As such, it is important to create an individualized treatment plan that is convenient, acceptable and maintainable for each patient.

\section{Mucus hydrators: hypertonic saline and mannitol}

Administration of agents, such as hypertonic saline and dry powder mannitol, creates an osmotic gradient which draws water into the airway and rehydrates the ASL, increasing mucociliary clearance ${ }^{25}$. Osmotic agents have a different and possibly complementary mechanism of action to dornase alfa ${ }^{26}$.

This article is protected by copyright. All rights reserved. 


\section{Hypertonic saline}

Hypertonic saline (3-7\% sodium chloride [ $\mathrm{NaCl}]$ solution) has a higher osmotic pressure than isotonic saline $(0.9 \% \mathrm{NaCl})$ solution and is administered via a nebulizer ${ }^{25}$. In a randomized controlled trial comparing twice-daily administration of either hypertonic or isotonic saline over 48 weeks, there was no significant improvement in the primary outcome (rate of decline of $\mathrm{FEV}_{1}$ ), but some improvement in other secondary outcomes that may be important to people with CF, such as exacerbation rate. Participants who were allocated hypertonic saline had reduced frequency of pulmonary exacerbation and improved quality of life ${ }^{27}$. Furthermore, the effect of hypertonic saline was similar in those who used and did not use dornase alfa $^{27}$. A Cochrane systematic review confirmed that hypertonic saline had limited effect on lung function, but improved quality of life and reduced pulmonary exacerbations ${ }^{28}$.

It has been suggested that hypertonic saline can be administered before or during airway clearance techniques to potentially augment these strategies. Recent data from a small pilot study reported that there was no difference in lung clearance index when hypertonic saline was administered before or during airway clearance ${ }^{30}$.

The Infant Study of Inhaled Saline (ISIS) study examined hypertonic saline versus isotonic saline in 321 pre-school children with CF (between the ages of 4-60 months) and did not identify any significant difference in respiratory exacerbations, although both aerosols were well tolerated ${ }^{31}$. Hypertonic saline also resulted in a significant change in $\mathrm{FEV}_{0.5}$ in these children, suggesting a potential improvement in the airflow. However, further study with sensitive endpoints is warranted ${ }^{31}$.

Hypertonic saline has a good safety profile and acceptable tolerability in young and adult patients with CF. Some patients may experience oropharyngeal irritation, wheeze and bronchospasm, especially with higher concentrations and faster delivery ${ }^{32}$. Pre-treatment with a bronchodilator is recommended.

This article is protected by copyright. All rights reserved. 


\section{Mannitol}

Dry powder mannitol, a naturally occurring monosaccharide, has a similar osmotic effect to hypertonic saline and potentially hydrates the ASL when inhaled. Unlike dornase alfa and hypertonic saline, mannitol does not require refrigeration, nebulization, or routine equipment sterilization, thereby providing a more convenient treatment option ${ }^{33}$. Similar to hypertonic saline, inhaled mannitol can stimulate coughing and induce bronchospasm ${ }^{34}$.

Data from two randomized controlled trials comparing twice-daily inhaled mannitol to a placebo (very low dose mannitol for taste masking) demonstrated a small but significant improvement in $\mathrm{FEV}_{1}$ and a reduction in pulmonary exacerbation with no significant increase in the reporting of adverse events ${ }^{35,36}$. Sub-group analysis suggested that the benefit in respiratory function was limited to adults and not apparent in children or young adults $^{37}$.

In a subsequent study of children with CF aged 6-17 years, inhaled mannitol was well tolerated and associated with improvement in lung function and a decreased incidence of pulmonary exacerbations, irrespective of disease severity ${ }^{38}$.

A Cochrane systematic review concluded that there was moderate quality evidence that inhaled mannitol improved lung function over a 6-month treatment period, and limited evidence of improved quality of life in patients with $\mathrm{CF}^{39}$.

Dry powder mannitol is delivered via a breath-actuated device and therefore some patient technique is required ${ }^{14}$. An exploratory study was reassuring that the generation of optimal flow for mannitol inhalation was not an issue in patients with $\mathrm{CF}^{40}$.

\section{Direct comparisons between aerosolized airway clearance agents}

There have been no direct comparative effectiveness studies evaluating the three mucoactive agents described above. There has been some sub-group analysis of data within studies, but Cochrane systematic reviews have concluded that there is no high-quality evidence to recommend one agent above another ${ }^{15,39}$. The choice of muco-active agent is 
therefore one that requires a degree of clinical judgement. It is important that these decisions are made in partnership with patients with CF and their families and that all options are considered. Although all members of the multi-disciplinary team have a role in determining the best treatment regimen for an individual patient, the physiotherapist has a particularly important contribution to make, both in assessing new therapies and evaluating responses to specific interventions. The physiotherapist should assess a thorough history and direct observation of delivery as to which intervention the person with CF feels is most effective. There are several factors to assess in this process and physiotherapists are ideally placed to work in partnership and decide on the best option for an individual.

\section{Clinical use of airway clearance agents}

\section{Guideline recommendations}

In general, available guidelines for the management of CF recommend consideration of the use of dornase alfa and hypertonic saline as a routine component of airway clearance therapy for older patients with CF. In children below 5 years of age, dornase alfa and hypertonic saline should be considered based on an individual basis.

The European Cystic Fibrosis Society (ECFS) best practice guidelines consider dornase alfa as the only mucolytic agent with proven efficacy in CF and recommend long-term maintenance therapy with dornase alfa to maintain treatment effect ${ }^{26}$. The guidelines indicate potential use of hypertonic saline and mannitol in patients with CF - hypertonic saline is used in many patients with moderate-to-severe lung disease and is recommended by the CF Foundation guidelines, while the recently introduced mannitol has been shown to improve lung function and its powder formulation can potentially reduce treatment time $^{26}$. Since both agents can result in bronchospasm, the guidelines recommend pretreatment with a bronchodilator and tolerability testing prior to their long-term use ${ }^{26}$.

The UK National Institute for Health and Care Excellence (NICE) guidelines for the diagnosis and management of CF recommend dornase alfa as the first choice of mucoactive agent ${ }^{41}$. If clinical response is inadequate, hypertonic saline, alone or in combination with dornase alfa, should be considered. Dry powder mannitol for inhalation

This article is protected by copyright. All rights reserved. 
is recommended as an option in adults with declining lung function, who are intolerant of or have an inadequate response to dornase alfa, and for whom other osmotic agents are not considered appropriate ${ }^{41}$.

The guidelines published by the CF Foundation in the US recommend the long-term use of dornase alfa to preserve lung function and reduce exacerbations in patients with moderate to severe lung disease. Dornase alfa is also recommended for patients with asymptomatic or mild lung disease ${ }^{42}$. The chronic use of hypertonic saline was also recommended for individuals with CF, 6 years of age and older; whereas no recommendation was made for mannitol ${ }^{42}$. Based on the moderate quality evidence for children under the age of 5 years old, the CF Foundation guidelines recommend that dornase alfa use in these young patients be considered based on individual circumstances $^{43,44}$. Similarly, inhaled hypertonic saline in patients aged 2-5 years should be selectively used based on individual assessment ${ }^{44}$.

In Australia, hypertonic saline is administered widely and without restriction with efficacy determined by patients, families and the care team. The subsidized use of dornase alfa and mannitol is guided by criteria from the Pharmaceutical Benefits Scheme. Subsidized use of dornase alfa is limited to 3 months at a dose of $2.5 \mathrm{mg}$ daily. For continued use, patients need to demonstrate clinical benefit and no deterioration of FEV . $_{\text {. }}$ Initiation of subsidized dornase alfa therapy in patients under 5 years of age is limited to those who have severe clinical conditions, including frequent exacerbations, significant bronchiectasis, CF bronchiolitis non-responsive to conventional medicines, and severe physiological respiratory deficit ${ }^{45}$. Subsidized mannitol is generally used in patients with CF 6 years of age or older who are intolerant or inadequately responsive to dornase alfa. Initial mannitol therapy is limited to 3 months at a dose of $400 \mathrm{mg}$ twice-daily. Continued use of mannitol depends on achieving criteria similar to those of dornase alfa ${ }^{46}$.

\section{Optimizing treatment outcomes for patients with CF}

Dornase alfa is approved in Europe, the US and Australia. Hypertonic saline is commonly used in Europe, US and Australia. Mannitol is approved for use in Europe and Australia but is not yet approved by the US FDA.

This article is protected by copyright. All rights reserved. 
Due to the insufficient high-quality evidence to determine the superiority of one agent over the other ${ }^{15,39}$, guidelines generally do not provide any recommendations on which agent should be initiated first. Evidence comparing inhaled dornase alfa and hypertonic saline is low quality; however, supported by clinical expertise and experience, the NICE guideline committee considered dornase alfa as more effective and tolerable compared with hypertonic saline and that there was insufficient evidence to change the currently accepted practice $^{41}$. As such, the guideline recommends dornase alfa as the first treatment choice $^{41}$.

As these agents have different mechanisms of action, there may be benefit from using more than one ${ }^{24}$. The effect of hypertonic saline was independent of dornase alfa ${ }^{27}$, while pooled data suggested that mannitol may provide additional benefit in improving lung function in patients who were already treated with dornase alfa ${ }^{37}$.

Whilst there is a clear indication for the use of muco-active agents in older patients with established CF airways disease, the evidence base is less robust in patients with minimal or no detectable airways disease. In these patients, it is important to have open and clear discussions with the patient and their family and involve them in joint decision making. Not engaging with the patient and family will have a negative influence on adherence to these long-term therapies. There should be clear consideration to the factors impacting on adherence, including daily routine and resources in the family. Visual aids, such as chest imaging (X-rays and high-resolution computerized tomograms [HRCT]) and bronchoscopy recordings, may act as modalities that can be used to explain the rationale for long-term aerosolized therapy and promote adherence.

\section{Adherence}

Treatment adherence is important for improving patient outcomes but adherence rates to aerosolized agents for airway clearance are generally low. The reported adherence to dornase alfa was 59\%; however, this was measured based on prescription fills and not observed medication use ${ }^{47}$. In another study, $82 \%$ of patients with CF claimed to use dornase alfa more than 20 days/month, but only $24 \%$ of patients were recorded to collect sufficient prescriptions ${ }^{48}$, highlighting the difficulty in accurately measuring treatment

This article is protected by copyright. All rights reserved. 
adherence. The adherence to hypertonic saline and dornase alfa in children ranged between 55-83\%, with lower adherence rates in older age group (13-21 years old) ${ }^{49}$. To enhance adherence, it is important for the CF team to understand the factors influencing adherence patterns, such as patient's perception and understanding of disease, patient's age, treatment complexity, and family support ${ }^{50}$. The CF team should utilize all available tools to support families and engage in shared decision making to optimize success on an individual basis ${ }^{50,51}$.

\section{Aerosolized agents for airway clearance in CF}

- Aerosolized dornase alfa is an established component of CF care, with good quality evidence of a significant effect on respiratory function in people with CF who have moderate or severe airways disease. It is well tolerated but requires commitment from the patient for successful long-term adherence.

- Hypertonic saline has been shown to be an effective and safe therapy for older children and adults with CF and is a low-cost intervention. Hypertonic saline is used in patients with moderate-to-severe lung disease and is recommended by guidelines.

- Mannitol is an alternative osmotic agent, with evidence suggesting benefit in older children and adults with CF. Long-term impact of mannitol remains to be established, but its dry powder formulation provides a more convenient treatment option.

\section{Questions to be answered}

There are several questions concerning the currently available muco-active agents:

- What is the optimal dose and frequency of dornase alfa to reduce treatment burden in patients with CF and optimize adherence?

- Does twice-daily use of dornase alfa in patients with pulmonary exacerbations or severe lung disease provide additional benefit?

- What is the role of dornase alfa, hypertonic saline and mannitol in asymptomatic patients with no evidence of airways disease?

- Does the early use of muco-active agents (dornase alfa, hypertonic saline and mannitol) simply arrest the progress of CF airways disease or are these agents

This article is protected by copyright. All rights reserved. 
disease-modifying (i.e., would early use of any of these agents prevent the onset of bronchiectasis)?

In summary, dornase alfa, hypertonic saline and mannitol are inhaled agents that have each been shown to demonstrate pulmonary benefits in CF by improving mucus clearance, which is a primary defect in CF. Their relative effectiveness (alone or in combination) has not been clearly established, but they all represent viable treatment options to manage airway disease in CF. Successful long-term use of these agents depends on clear partnership - working with patients with CF and their families to engage in shared decision making, for improved adherence and better outcomes.

\section{References}

1. Pittman JE, Ferkol TW. The evolution of cystic fibrosis care. Chest 2015;148(2):53342.

2. Hoegger MJ, Fischer AJ, McMenimen JD, Ostedgaard LS, Tucker AJ, Awadalla MA, Moninger TO, Michalski AS, Hoffman EA, Zabner J, et al. Impaired mucus detachment disrupts mucociliary transport in a piglet model of cystic fibrosis. Science 2014;345(6198):818-22.

3. Tang XX, Ostedgaard LS, Hoegger MJ, Moninger TO, Karp PH, McMenimen JD, Choudhury B, Varki A, Stoltz DA, Welsh MJ, et al. Acidic pH increases airway surface liquid viscosity in cystic fibrosis. J Clin Invest 2016;126(3):879-91.

4. De Boeck K, Amaral MD. Progress in therapies for cystic fibrosis. Lancet Respir Med 2016;4(8):662-74.

5. Henke MO, Ratjen F. Mucolytics in cystic fibrosis. Paediatr Respir Rev 2007;8(1):249.

6. Spielberg DR, Clancy JP. Cystic fibrosis and its management through established and emerging therapies. Annu Rev Genomics Hum Genet 2016;17:155-75.

7. Shak S, Capon DJ, Hellmiss R, Marsters SA, Baker CL. Recombinant human DNase I reduces the viscosity of cystic fibrosis sputum. Proc Natl Acad Sci U.S.A 1990;87(23):9188-92.

This article is protected by copyright. All rights reserved. 
8. Aitken ML, Burke W, McDonald G, Shak S, Montgomery AB, Smith A. Recombinant human DNase inhalation in normal subjects and patients with cystic fibrosis. A phase 1 study. JAMA 1992;267(14):1947-51.

9. Shah PL, Scott SF, Knight RA, Marriott C, Ranasinha C, Hodson ME. In vivo effects of recombinant human DNase I on sputum in patient with cystic fibrosis. Thorax 1996;51(2):119-25.

10. Dornase alfa prescribing information. 2018.

https://www.gene.com/download/pdf/pulmozyme_prescribing.pdf. Accessed on 3 April 2018.

11. Fuchs HJ, Borowitz DS, Christiansen DH, Morris EM, Nash ML, Ramsey BW, Ramsey BW, Rosenstein BJ, Smith AL, Wohl ME. Effect of aerosolized recombinant human DNase on exacerbations of respiratory symptoms and on pulmonary function in patients with cystic fibrosis. The Pulmozyme Study Group. N Engl J Med 1994;331(10):637-42.

12. Shah PL, Bush A, Canny GJ, Colin AA, Fuchs HJ, Geddes DM, Johnson CA, Light MC, Scott SF, Tullis DE. Recombinant human DNase I in cystic fibrosis patients with severe pulmonary disease: a short-term, double-blind study followed by six months open-label treatment. Eur Respir J 1995;8(6):954-8.

13. McCoy K, Hamilton S, Johnson C. Effects of 12-week administration of dornase alfa in patients with advanced cystic fibrosis lung disease. Pulmozyme Study Group. Chest 1996;110(4):889-95.

14. Konstan MW, Wagener JS, Pasta DJ, Millar SJ, Jacobs JR, Yegin A, Morgan WJ; Scientific Advisory Group and Investigators and Coordinators of Epidemiologic Study of Cystic Fibrosis. Clinical Use of Dornase Alfa Is Associated with a Slower Rate of $\mathrm{FEV}_{1}$ Decline in Cystic Fibrosis. Pediatr Pulmonol 2011;46(6):545-53.

15. Yang C, Chilvers M, Montgomery M, Nolan SJ. Dornase alfa for cystic fibrosis. Cochrane Database Syst Rev 2016;4:CD001127.

16. Hodson ME, McKenzie S, Harms HK, Koch C, Mastella G, Navarro J, Strandvik B; Investigators of the Epidemiologic Registry of Cystic Fibrosis. Dornase alfa in the treatment of cystic fibrosis in Europe: a report from the Epidemiologic Registry of Cystic Fibrosis. Pediatr Pulmonol 2003;36(5):427-32.

This article is protected by copyright. All rights reserved. 
17. Paul K, Rietschel E, Ballmann M, Griese M, Worlitzsch D, Shute J, Chen C, Schink T, Döring G, van Koningsbruggen S, et al. Effect of treatment with dornase alpha on airway inflammation in patients with cystic fibrosis. Am J Respir Crit Care Med 2004;169(6):719-25.

18. Ratjen F, Paul K, van Koningsbruggen S, Breitenstein S, Rietschel E, Nikolaizik W. DNA concentrations in BAL fluid of cystic fibrosis patients with early lung disease: influence of treatment with dornase alpha. Pediatr Pulmonol 2005;39(1):1-4.

19. Quan JM, Tiddens HA, Sy JP, McKenzie SG, Montgomery MD, Robinson PJ, Wohl ME, Konstan MW; Pulmozyme Early Intervention Trial Study Group. A two-year randomized, placebo-controlled trial of dornase alfa in young patients with cystic fibrosis with mild lung function abnormalities. J Pediatr 2001;139(6):813-20.

20. Amin R, Subbarao P, Lou W, Jabar A, Balkovec S, Jensen R, Kerrigan S, Gustafsson $P$, Ratjen F. The effect of dornase alfa on ventilation inhomogeneity in patients with cystic fibrosis. Eur Respir J 2011;37(4):806-12.

21. McKenzie SG, Chowdhury S, Strandvik B, Hodson ME; Investigators of the Epidemiologic Registry of Cystic Fibrosis. Dornase alfa is well tolerated: data from the epidemiologic registry of cystic fibrosis. Pediatr Pulmonol 2007;42(10):928-37.

22. Dentice R, Elkins M. Timing of dornase alfa inhalation for cystic fibrosis. Cochrane Database Syst Rev 2016;7:CD007923.

23. Suri R, Metcalfe C, Lees B, Grieve R, Flather M, Normand C, Thompson S, Bush A, Wallis C. Comparison of hypertonic saline and alternate-day or daily recombinant human deoxyribonuclease in children with cystic fibrosis: a randomised trial. Lancet 2001;358(9290):1316-21.

24. Bilton D, Stanford G. The expanding armamentarium of drugs to aid sputum clearance: how should they be used to optimize care? Curr Opin Pulm Med 2014;20(6):601-6.

25. Tildy BE, Rogers DF. Therapeutic options for hydrating airway mucus in cystic fibrosis. Pharmacology 2015;95(3-4):117-32.

26. Castellani C, Duff AJA, Bell SC, Heijerman HGM, Munck A, Ratjen F, SermetGaudelus I, Southern KW, Barben J, Flume PA, et al. ECFS best practice guideline: the 2018 revision. J Cyst Fibros 2018;17(2):153-78.

This article is protected by copyright. All rights reserved. 
27. Elkins MR, Robinson M, Rose BR, Harbour C, Moriarty CP, Marks GB, Belousova EG, Xuan W, Bye PT; National Hypertonic Saline in Cystic Fibrosis (NHSCF) Study Group. A controlled trial of long-term inhaled hypertonic saline in patients with cystic fibrosis. N Engl J Med 2006;354(3):229-40.

28. Wark P, McDonald VM. Nebulised hypertonic saline for cystic fibrosis. Cochrane Database Syst Rev 2009;2:CD001506.

29. Elkins M, Dentice R. Timing of hypertonic saline inhalation for cystic fibrosis. Cochrane Database Syst Rev 2016;12:CD008816.

30. O’Neill K, Moran F, Tunney MM, Elborn JS, Bradbury I, Downey DG, Rendall J, Bradley JM. Timing of hypertonic saline and airway clearance techniques in adults with cystic fibrosis during pulmonary exacerbation: pilot data from a randomised crossover study. BMJ Open Respir Res 2017;4(1):e000168.

31. Rosenfeld M, Ratjen F, Brumback L, Daniel S, Rowbotham R, McNamara S, Johnson R, Kronmal R, Davis SD; ISIS Study Group. Inhaled hypertonic saline in infants and children younger than 6 years with cystic fibrosis: the ISIS randomized controlled trial. JAMA 2012;307(21):2269-77.

32. Goralski JL, Donaldson SH. Hypertonic saline for cystic fibrosis: worth its salt? Expert Rev Respir Med 2014;8(3):267-9.

33. Nolan SJ, Thornton J, Murray CS, Dwyer T. Inhaled Mannitol (Bronchitol) for Cystic Fibrosis. Paediatr Respir Rev 2016;18:52-4.

34. Flume PA, Aitken ML, Bilton D, Agent P, Charlton B, Forster E, Fox HG, Hebestreit $\mathrm{H}$, Kolbe J, Zuckerman JB. et al. Optimising inhaled mannitol for cystic fibrosis in an adult population. Breathe (Sheff) 2015;11(1):39-48.

35. Bilton D, Robinson P, Cooper P, Gallagher CG, Kolbe J, Fox H, Jaques A, Charlton B; CF301 Study Investigators. Inhaled dry powder mannitol in cystic fibrosis: an efficacy and safety study. Eur Respir J 2011;38(5):1071-80.

36. Aitken ML, Bellon G, De Boeck K, Flume PA, Fox HG, Geller DE, Haarman EG, Hebestreit HU, Lapey A, Schou IM, et al. Long-term inhaled dry powder mannitol in cystic fibrosis: an international randomized study. Am J Respir Crit Care Med 2012;185(6):645-52.

This article is protected by copyright. All rights reserved. 
37. Bilton D, Bellon G, Charlton B, Cooper P, De Boeck K, Flume PA, Fox HG, Gallagher CG, Geller DE, Haarman EG, et al.Pooled analysis of two large randomised phase III inhaled mannitol studies in cystic fibrosis. J Cyst Fibros 2013;12(4):367-76.

38. De Boeck K, Haarman E, Hull J, Lands LC, Moeller A, Munck A, Riethmüller J, Tiddens H, Volpi S, Leadbetter J, et al. Inhaled dry powder mannitol in children with cystic fibrosis: A randomised efficacy and safety trial. J Cyst Fibros 2017;16(3):3807.

39. Nevitt SJ, Thornton J, Murray CS, Dwyer T. Inhaled mannitol for cystic fibrosis. Cochrane Database Syst Rev 2018;2:CD008649.

40. Elkins MR, Robinson O, Anderson SD, Perry CP, Daviskas E, Charlton B. Inspiratory flows and volumes in subjects with cystic fibrosis using a new dry powder inhaler device. Open Respir Med J 2014;8:1-7.

41. National Institute for Health and Care Excellence. Cystic fibrosis: diagnosis and management. NICE guideline 2017. https://www.nice.org.uk/guidance/ng78/resources/cystic-fibrosis-diagnosis-andmanagement-pdf-1837640946373. Accessed on 3 April 2018.

42. Mogayzel PJ, Naureckas ET, Robinson KA, Mueller G, Hadjiliadis D, Hoag JB, Lubsch L, Hazle L, Sabadosa K, Marshall B; Pulmonary Clinical Practice Guidelines Committee. Cystic fibrosis pulmonary guidelines. Chronic medications for maintenance of lung health. Am J Respir Crit Care Med 2013;187(7):680-9.

43. Cystic Fibrosis Foundation, Borowitz D, Robinson KA, Rosenfeld M, Davis SD, Sabadosa KA, Spear SL, Michel SH, Parad RB, White TB, et al. Cystic Fibrosis Foundation evidence-based guidelines for management of infants with cystic fibrosis. J Pediatr 2009;155(6 Suppl):S73-93.

44. Lahiri T, Hempstead SE, Brady C, Cannon CL, Clark K, Condren ME, Guill MF, Guillerman RP, Leone CG, Maguiness K, et al. Clinical Practice Guidelines from the cystic fibrosis foundation for preschoolers with cystic fibrosis. Pediatrics 2016;137(4). Pii:e20151784.

45. The Pharmaceutical Benefits Scheme. Dornase Alfa. "Authority Required”. http://www.pbs.gov.au/medicine/item/5704F-6120D. Accessed on 20 April 2018.

This article is protected by copyright. All rights reserved. 
46. The Pharmaceutical Benefits Scheme. Mannitol. "Authority Required”. http://www.pbs.gov.au/medicine/item/2008Q-2015C. Accessed on 20 April 2018.

47. Nasr SZ, Chou W, Villa KF, Chang E, Broder MS. Adherence to dornase alfa treatment among commercially insured patients with cystic fibrosis. J Med Econ 2013;16(6):801-8.

48. Burrows JA, Bunting JP, Masel PJ, Bell SC. Nebulised dornase alpha: adherence in adults with cystic fibrosis. J Cyst Fibros 2002;1(4):255-9.

49. Shakkottai A, Kidwell KM, Townsend M, Nasr SZ. A five-year retrospective analysis of adherence in cystic fibrosis. Pediatr Pulmonol 2015;50(12):1224-9.

50. Ohn M, Fitzgerald DA. Question 12: what do you consider when discussing treatment adherence in patients with cystic fibrosis? Paediatr Respir Rev 2018;25:33-6.

51. Narayanan S, Mainz JG, Gala S, Tabori H, Grossoehme D. Adherence to therapies in cystic fibrosis: a targeted literature review. Expert Rev Respir Med 2017;11(2):12945.

This article is protected by copyright. All rights reserved. 


\section{Figure}

Figure. Airway surface liquid (ASL) dehydration in cystic fibrosis. The malfunctioning of CFTR protein, accompanied by fluid absorption via the epithelial sodium channel (ENaC), disrupts ion transport and water efflux across cell membranes, resulting in dehydration of the ASL and abnormal mucus. Mucociliary clearance impairment leads to mucus accumulation and airway obstruction, and inflammation due to bacterial invasion. Airway clearance agents, such as rhDNase degrades the polymerized DNA from dead and dying neutrophils in CF mucus (inset); while mucus hydrators, such as hypertonic saline and mannitol, draw water into the airway by creating an osmotic gradient ${ }^{1-3,5}$.

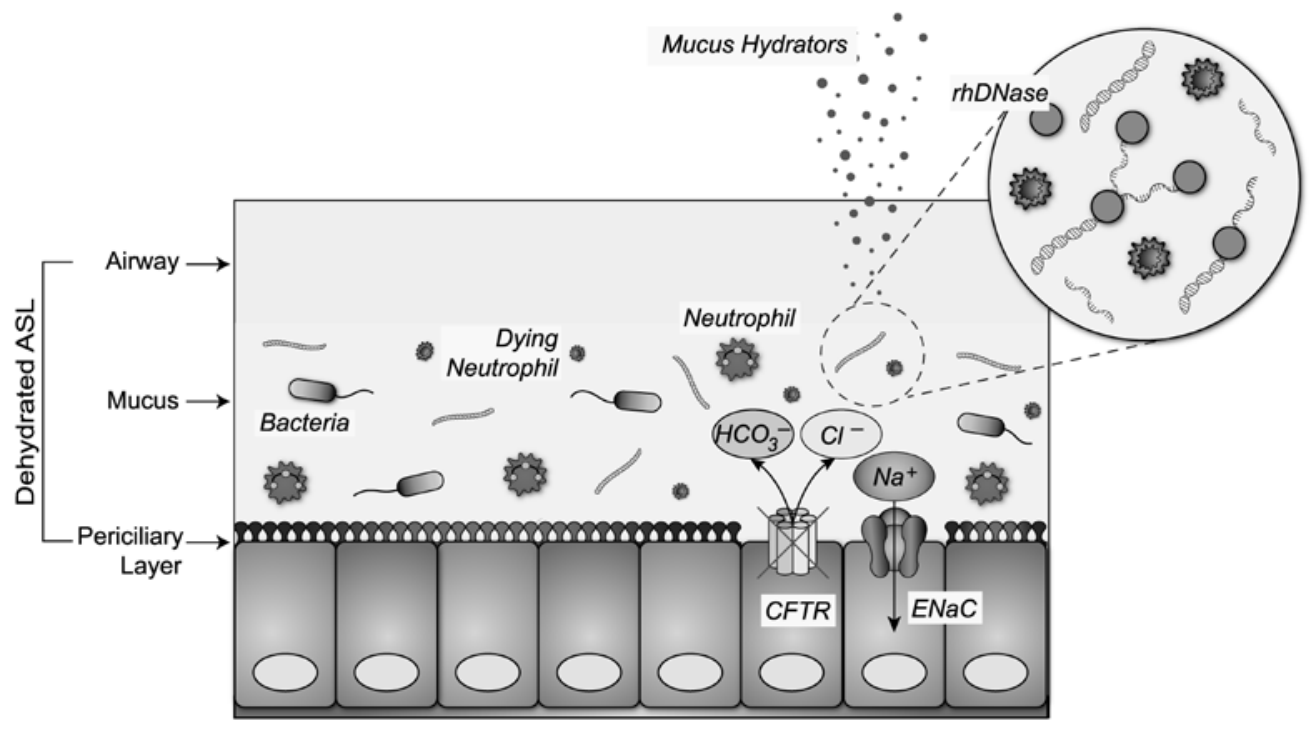

This article is protected by copyright. All rights reserved. 


\section{University Library}

\section{- M M I E R R A A gateway to Melbourne's research publications}

Minerva Access is the Institutional Repository of The University of Melbourne

Author/s:

Southern, KW;Clancy, JP;Ranganathan, S

Title:

Aerosolized agents for airway clearance in cystic fibrosis

Date:

2019-06-01

Citation:

Southern, K. W., Clancy, J. P. \& Ranganathan, S. (2019). Aerosolized agents for airway clearance in cystic fibrosis. PEDIATRIC PULMONOLOGY, 54 (6), pp.858-864. https:// doi.org/10.1002/ppul.24306.

Persistent Link:

http://hdl.handle.net/11343/285596 